\title{
LA VIOLENCIA CONTRA LAS MUJERES: CONCEPTOS Y CAUSAS
}

THE VIOLENCE AGAINST WOMEN: CONCEPTS AND CAUSES

\author{
Antonio Jesús Yugueros García \\ Universidad Pablo de Olavide, Sevilla. España/Spain \\ antyugue@hotmail.com
}

Recibido/Received: 27/03/2014

Modificado/Modified: 30/05/2014

Aceptado/Accepted: 27/06/2014

\section{RESUMEN}

El estudio de la violencia contra las mujeres es de carácter multidisciplinar desde el punto de vista académico, ya que afecta a varios ámbitos de las diferentes ciencias, por ello se hace necesario realizar, previamente, un encuadre metodológico, para no desviarnos del área que se pretenda estudiar. Concretamente, en este artículo, se va a proponer una aproximación al concepto de violencia de género, diferenciándolo de la denominada violencia doméstica. También se expondrán los distintos tipos de violencia que pueden padecer las mujeres, y por último se estudiará la causa última de esta violencia estructural llevada a cabo en el seno de las relaciones de pareja o expareja.

\section{PALABRAS CLAVE}

Violencia de género, conceptos, pareja, mitos, estereotipos.

\section{SUMARIO}

1. Introducción. 2. La violencia de género en las relaciones de pareja. 3. Tipos de violencia que pueden padecer las mujeres. 4. Ciclo de la violencia en las relaciones de pareja. 5. Mitos y estereotipos de género. 6. Conclusiones. Bibliografía.

\section{ABSTRACT}

The study of violence against women is multidisciplinary from the academic point of view, since it affects several aspects of the different sciences, so it is necessary to make previously a methodological frame, not to deviate the box under investigation. Specifically, this article is to propose an approach to the concept of gender violence, as distinct from the so-called domestic violence. Different types of violence that women may have will also be exhibited, and finally the ultimate cause of this structural violence carried out within the partner or former partner relationships will be studied.

\section{KEYWORDS}

Violence, concepts, couple, myths, stereotypes.

\section{CONTENTS}

1. Introduction. 2. Gender violence in relationships. 3. Types of violence that women may have. 4. Cycle of violence in intimate relationships. 5. Myths and gender stereotypes. 6. Conclusions. References. 


\section{INTRODUCCIÓN}

En el campo de las intervenciones sociales, como en cualquier otra área del conocimiento, es necesario nombrar y delimitar adecuadamente los casos o sujetos a tratar, pues, inexorablemente, conceptos diferentes supondrán métodos de intervención también distintos.

Por otra parte denominar inadecuadamente los problemas que se están abordando, por no encuadrarlos adecuadamente en el ámbito del saber del que le son objeto, o conceptualizarlos de forma unívoca, puede dar lugar, por un lado, a no visibilizar la problemática que se analiza, y por otra, aglutinar en un mismo concepto distintos problemas, que requieren formas diferentes de actuación, pueden constituir un menoscabo para las personas implicadas en estos hechos, victimizándolas doblemente.

\subsection{Violencia de Género: concepto de las Naciones Unidas}

La Declaración sobre la Eliminación de la Violencia contra la Mujer, aprobada en Resolución de la Asamblea General de Naciones Unidas 48/104, del 20 de diciembre de 1993, publicada el 23 de febrero de 1994 (ONU,1993) es el primer documento a nivel internacional, que aborda de manera clara y específica esta tipología de violencia, definiendo en su artículo primero que la violencia contra la mujer es todo acto de violencia basado en la pertenencia al sexo femenino, que tenga o pueda tener como resultado un daño o sufrimiento físico, sexual o psicológico para la mujer, así como las amenazas de tales actos, la coacción o la privación arbitraria de la libertad, tanto si se produce en la vida pública como en la vida privada.

Igualmente, expone esta importante Declaración, los actos que constituyen violencia contra las mujeres, aunque el abanico de actos punibles no se limita a los que se indican a continuación, sino que es más amplio, como posteriormente se relatará:

1. La violencia física, sexual y psicológica que se produce en la familia, incluidos los malos tratos, el abuso sexual de las niñas en el hogar, la violencia relacionada con la dote, la violencia por el marido, la mutilación genital femenina y otras prácticas tradicionales nocivas para la mujer, los actos de violencia perpetrados por otros miembros de la familia y la violencia relacionada con la explotación.

2. La violencia física, sexual y psicológica perpetrada dentro de la comunidad en general, inclusive la violación, el abuso sexual, el acoso y la intimidación sexual en el trabajo, en instituciones educacionales y en otros lugares, la trata de mujeres y la prostitución forzada.

3. La violencia física, sexual y psicológica perpetrada o tolerada por el Estado, dondequiera que ocurra.

Lo primero que llama la atención al estudiar este precepto legislativo internacional, es que se observa que los conceptos violencia de género y violencia contra las mujeres son sinónimos, y que esta tipología de la violencia no se circunscribe a un lugar determinado donde se produce o pueda producirse el elenco de conductas violentas descritas en ella, sino que va dirigida hacia las mujeres, por el simple hecho de ser mujeres, esta es precisamente la especificidad de este tipo de violencia (Maqueda, 2006; Peris, 2009).

Esta cuestión es importante, porque se tiende a identificar como violencia de género solamente como la que se produce en las relaciones de pareja o expareja, y esta anomalía produce varios inconvenientes, como no hacer visible aquellas violencias que se llevan a cabo en las relaciones de pareja donde no existe convivencia, por ejemplo las de noviazgo, entre adolescentes (Leal, 2008; IAM, 2009; Lorente, 2010) o integra a la violencia contra las mujeres con otro tipos de violencias que se producen en el ámbito familiar, por ejemplo, se equipararía la violencia ejercida hacia las mujeres por el hombre pareja o expareja (violencia 
de género), con la que se da entre otros miembros del entorno familiar entre hermanas/os, padres hijos/as (violencia doméstica), (Varela, 2008; Amorós, 2011).

Además, esta inadecuación conceptual, a veces interesada, entre violencia de género y violencia doméstica, contribuye a perpetuar la probada resistencia social a reconocer que el maltrato a las mujeres, no es circunstancial ni neutra, sino instrumental y útil en aras a mantener un determinado orden de valores estructuralmente discriminatorio para las mujeres (De Miguel, 2005; Valcárcel, 2011).

A la mujer no se le maltrata por ser madre, novia o ama de casa, sino por ser mujer, por ello es importante delimitar conceptualmente la violencia que se ejerce sobre la mujer, ya que al denominarla incorrectamente, por ejemplo como "violencia doméstica" o "violencia familiar", se está relacionando sólo con un ambiente concreto, el familiar o el doméstico, y de ahi se puede pasar con relativa facilidad a limitarlo a determinados tipos de familia, a ciertas circunstancias, a algunos hombres que son enfermos, alcohólicos o especialmente violentos, o también a mujeres que los provocan (Lorente, Lorente, 1998:85).

En definitiva la violencia de género resalta la cuestión cultural de su etiología, de ahí su calificativo género, no es una cuestión que tenga que ver con el ámbito donde se produce la misma, como el doméstico, sino a las personas a las que van dirigidas, las mujeres.

El movimiento feminista, y los movimientos de mujeres, hacen mucho hincapié en esta cuestión, pues es de vital importancia nombrar adecuadamente los conceptos, para poder visibilizar de manera notoria que la violencia de género es producto de las desigualdades entre hombres y mujeres (Valpuesta, 2008), de esta manera consideran que otros términos sinónimos para denominar la violencia contra las mujeres serían: violencia sexista, violencia machista, violencia patriarcal, etc., pero en ningún caso violencia doméstica.

También, desde el punto de vista penal, la violencia de género y violencia doméstica están preceptuados de forma diferente (Rodríguez, 2008, Acale, 2009), el primer caso en el artículo 153.1 del Código Penal (CP, 1995), que literalmente, en la parte que interesa dice:

El que por cualquier medio o procedimiento causare a otro menoscabo psíquico o una lesión no definidos como delito en este Código, o golpeare o maltratare de obra a otro sin causarle lesión, cuando la ofendida sea o haya sido esposa, o mujer que esté o haya estado ligada a él por una análoga relación de afectividad aun sin convivencia, o persona especialmente vulnerable que conviva con el autor....

La violencia doméstica está tipificada en el artículo 153.2 del vigente Código Penal (1995), que textualmente preceptúa:

Si la víctima del delito previsto en el apartado anterior fuere alguna de las personas a que se refiere el art. 173.2, exceptuadas las personas contempladas en el apartado anterior de este artículo....

A tal efecto, las personas a las que hace referencia el art. 173.2, invocado en el párrafo anterior, exceptuando, la mujer pareja o expareja, que queda encuadrada dentro del art. 153.1, son": descendientes, ascendientes; hermanos por naturaleza, adopción o afinidad, propios o del cónyuge; menores o incapaces que con él convivan o que se hallen sujetos a la potestad, tutela o curatela, acogimiento o guarda de hecho del cónyuge o conviviente, o sobre persona amparada en cualquier otra relación por la que se encuentre integrada en el núcleo de la 
convivencia familiar, así como sobre las personas que por su especial vulnerabilidad se encuentren sometidas a custodia o guarda en centros públicos o privados..."

Si existiese habitualidad en los casos descritos anteriormente, el Código Penal nos derivaría al art. 173.2.

\subsection{Violencia de Género, concepto según la Ley 1/2004}

En ocasiones, las denominaciones violencia de género y violencia doméstica, provocan confusión, esto es debido a que la Ley Orgánica 1/2004, de 28 de diciembre, de Medidas de Protección Integral contra la Violencia de Género (LO. 1/2004) en su artículo primero, enuncia que esta violencia es una manifestación de la discriminación y situación de desigualdad entre las relaciones de poder de los hombres sobre las mujeres, en las relaciones de pareja o expareja, es decir, reduce la violencia de género a los ilícitos penales tipificados en la invocada ley, cometidos por los hombres pareja o expareja de la mujer víctima.

Quizás la definición dada por la LO.1/2004, se hizo con el propósito de diferenciarla de la violencia doméstica, pues, esta ley da cuenta de quién puede ser autor de estas ilícitas conductas, y no se circunscribe al ámbito del hogar, como anteriormente se venía haciendo, sin embargo, dejó fuera de su concepto los demás hechos que preceptúa la repetida Declaración 48/104. En positivo hay que decir que la promulgación de esta LO. 1/2004, ha sido un gran avance en la erradicación de esta lacra social, por la consolidación de derechos, de forma integral, de las mujeres víctimas, así como la implementación de medidas de seguridad y protección para ellas.

\section{LA VIOLENCIA DE GÉNERO EN LAS RELACIONES DE PAREJA}

La violencia de género en las relaciones de pareja, han formado parte de la vida cotidiana de las mujeres a lo largo de los tiempos, estaba naturalizada, silenciada, lo que la hacía invisible (Nogueiras, 2006; Melero, 2010), con lo cual no estaba reconocida socialmente. Nadie la veía ni la nombraba, incluso las mismas víctimas lo consideraban un asunto de dominio privado; aunque en la actualidad se ha avanzado bastante en la sensibilización ante esta problemática social, todavía existe una actitud silenciosa ante los casos que se dan habitualmente en nuestra sociedad.

Gracias a la denodada lucha de los movimientos feministas y de mujeres, se han podido visibilizar estos hechos, haciendo que pasen a formar parte del ámbito público, instando ante los poderes públicos a que se promulgaran leyes encaminadas a la eliminación de este tipo de violencia, y a que se implementaran medidas de protección integral a las mujeres víctimas de esta violencia patriarcal.

Para acercarnos a las posibles causas de la violencia que padecen las mujeres en las relaciones de pareja o expareja, y diferenciarla de otra tipología de violencia interpersonal, es necesario ir a la raíz de la conducta humana, es decir, toda conducta tiene dos componentes: el instrumental y el emocional, el primero se pregunta por qué y para qué de dicha conducta, qué se pretende conseguir con ella y qué nos mueve a realizarla. (Lorente, 2004). Por su parte, el componente emocional se refiere a la carga afectiva, que se pone al llevar a cabo dicha conducta: rabia, odio alegría.

$\mathrm{Al}$ analizar las agresiones que sufren las mujeres en el contexto de pareja, considerando los elementos instrumental y emocional descritos anteriormente, se observa que se trata de una conducta totalmente distinta al resto de las agresiones interpersonales, en este caso, queda de manifiesto que las mujeres son violentadas por el simple hecho de ser mujeres, no 
hay ninguna otra motivación, como ocurre en las demás formas de violencia. El fin último que pretende conseguir el maltratador con su conducta violenta, siguiendo a Miguel Lorente (2004), no es ocasionar unas determinadas lesiones, lo que realmente busca es "aleccionar" a la mujer, para que quede de forma expresa y clara que él es el que mantiene la autoridad en la relación, y determinar la situación que a ella le corresponde, que no es otra que la subordinación y sumisión a este hombre.

La mujer de esta forma, queda sometida a los criterios, voluntad y deseos del varón, al estar controlada por él, que le tiene que dar cuenta de sus actividades en el momento que considere conveniente. En definitiva el hombre desea mantener a la mujer bajo su control, venciendo su resistencia y quitándole poder, para lograr su sumisión y la dependencia psicológica, de forma que la violencia se convierte en un recurso de dominación directo y ejemplar, porque produce pánico de manera anticipada, parálisis, control o daños, según su intensidad (Bonino, 1999; Berbel, 2004).

Es por ello, que la violencia de género en las relaciones de pareja se la denomina violencia estructural, concepto acuñado por Galtung (2003), que postula que la violencia tiene una triple dimensión: directa, estructural y cultural. Estos tres conceptos los representó en un triángulo, que lo llamó el triángulo de la violencia, donde se indican los tres tipos diferentes de violencia existentes, que se encuentran relacionados entre sí. De tal manera que la violencia directa, se representaría en el vértice superior del triángulo, sería la violencia visible, la que es evidente a los sentidos, manifestada de manera física, verbal o psicológica.

La violencia estructural es característica de los sistemas sociales y de gobierno que dirigen los estados. Su relación con la violencia directa es proporcional a la parte del iceberg que se encuentra sumergida; y por último la violencia cultural, denominada también simbólica, ya que está sustentada por valores culturales tradicionales de muy distintos ámbitos: ciencias, religión, ideologías, himnos banderas, etc., en palabras de Galtung, sería la suma total de todos los mitos (Percy, 2009).

De lo expuesto sobre esta teoría (Galtung, 2003), se puede deducir, que la violencia de género, al estar revestida de las características estructurales definidas en este triángulo, a este autor se le antoja que luchar contra este problema social no es fácil, porque esta violencia forma parte del tejido social, al estar canalizado por la socialización cultural, esto sin embargo, no debe ser un obstáculo para arbitrar mecanismos de desestabilización de esta violencia, pero se quiere hacer hincapié de que no es un problema que se pueda solucionar con medidas paliativas, sino afrontando iniciativas que incidan de manera directa en los dos ámbitos de los que estamos tratando: cultual y estructural, es decir, educación, sensibilización e intervención social.

\section{TIPOS DE VIOLENCIA QUE PUEDEN PADECER LAS MUJERES}

En el Estudio sobre todas las formas de violencia contra la mujer, del Informe del Secretario General de la Asamblea General de las Naciones Unidas, de fecha 6 de julio de 2006, se enuncian las distintas formas de violencia que pueden padecer las mujeres, tratándose de las siguientes (ONU, 2006):

\subsection{Violencia contra la mujer en el ámbito de la pareja}

Es la forma de violencia más común que experimentan las mujeres en todo el mundo. Puede consistir en: 
a. Violencia física, que es el uso intencional de esta fuerza, pudiendo utilizar armas, con el objeto de dañar a la mujer.

b. Violencia psicológica, las controla, aísla y humilla. La violencia económica les niega el acceso a los recursos básicos.

c. Violencia sexual, que es la conducta por la cual se hace participar a la mujer en un acto sexual no consentido; realizarlo con una mujer incapacitada, o bajo los efectos de sustancias.

\subsection{Violencia contra la mujer dentro de la familia}

La violencia que padecen muchas mujeres en el seno de la familia, puede comprender desde el período antes del nacimiento hasta la ancianidad. Se manifiesta en:

a. Violencia física; violencia relacionada con la dote;

b. Infanticidio femenino; abuso sexual de las niñas en el hogar;

c. Ablación o mutilación genital; matrimonio precoz o forzado;

d. Violencia ejercida por otros miembros de la familia.

e. La violencia cometida contra las trabajadoras domésticas

f. Otras formas de explotación.

También, dentro de la familia, o al amparo de ésta, se cometen los denominados crímenes de "honor".

\subsection{Violencia contra la mujer en la comunidad}

a. Feminicidio o femicidio: el homicidio de una mujer por cuestiones de género.

b. Violencia sexual llevada a cabo fuera de la pareja.

c. Acoso sexual y violencia en el lugar de trabajo, demás instituciones y en el ámbito deportivo. Un 50\% aproximadamente de mujeres de la Unión Europea manifiestan haber sido acosadas en alguna ocasión en sus puestos de trabajo.

d. Trata de mujeres: la mayoría de las víctimas de trata de seres humanos en el mundo son mujeres y niños. El fin es la explotación sexual. Puede darse dentro del mismo país o a nivel internacional. (MSSSI, 2013).

e. Otras violencias: dedicación de las niñas pequeñas a templos. Las restricciones de la segunda hija a casarse. El matrimonio con el hermano del marido fallecido. El maltrato de las viudas, en particular la incitación a que se suiciden.

\subsection{Violencia contra la mujer cometida o tolerada por el Estado}

a. Violencia contra la mujer privada de libertad: es la que se lleva a cabo en prisiones, centros de bienestar social, etc.

b. Esterilización forzada: controla la reproducción de la población femenina, o de un subgrupo determinado.

\subsection{Violencia contra la mujer en conflictos armados}

Como consecuencia de las guerras, las mujeres padecen todo tipo de violencia física, sexual y psicológica, comprendiendo:

a. Homicidios, torturas, raptos, mutilaciones y desfiguraciones, reclutamiento forzado de mujeres combatientes;

b. Violaciones, esclavitud sexual, explotación sexual, prostitución forzada;

c. Desapariciones involuntarias, prisiones arbitrarias, matrimonios forzados;

d. Abortos forzados, embarazos forzados; esterilización compulsiva. 


\section{CICLO DE LA VIOLENCIA EN LAS RELACIONES DE PAREJA}

Es importante conocer este ciclo, para entender en qué estado psicológico se encuentran las mujeres que están sufriendo malos tratos habituales, a veces durante muchos años, y se personan ante los profesionales asistenciales para requerir protección y ayuda al objeto de salir del entorno hostil en el que viven.

Walter (1979), explica y nos ayuda a entender cómo se produce y mantiene la violencia en la pareja. Esta autora trabajó en una casa refugio para mujeres maltratadas, y observó que muchas de ellas describían un patrón muy parecido en el proceso de maltrato y que éste tenía una forma cíclica, que se desarrollaba en tres fases concretas, que más adelante se van a indicar. (Walter, 1979; Cantera, 1999; Nogueiras, 2006; Paz, 2011).

Desde esta perspectiva es fácil entender que a estas mujeres víctimas, a las que se les ha anulado su personalidad, como consecuencia de la violencia psicológica a la que han estado sometidas durante un largo período de tiempo e incluso años, y ni tan siquiera han sido conscientes de tal circunstancia, hasta que se han desencadenado los malos tratos físicos de forma virulenta, o se ha maltratado a sus hijos/as, se presente a los pocos días de interponer una denuncia a retirar la misma, renunciando a continuar con el proceso judicial (Cala, 2012), o tras una orden de alejamiento reanude la relación con su pareja o expareja.

Esto no quiere decir que la mujer sea irracional (Larrauri, 2008), sino que en ese momento se encuentra en un estado psicológico que le impide actuar con adecuación a la situación adversa por la que está atravesando, pero este estado de desconcierto, le ocurre también, a cualquier persona que en un momento dado ha sido víctima de un hecho delictivo, tanto en su persona como en sus propiedades, denominado Síndrome de Estrés Postraumático.

El maltrato suele comenzar con conductas de abuso psicológico, difíciles de identificar porque están enmascaradas en apariencia de cariño y afecto. Estos comportamientos restrictivos y controladores van socavando la capacidad de decisión y autonomía de las mujeres. Los celos, la censura sobre la ropa que usa habitualmente, las amistades, las actividades, los horarios y las salidas de casa, son ejemplos claros de lo que se está enunciando.

Estas conductas van produciendo dependencia y aislamiento, no siendo percibidas como agresivas, sino como pruebas de amor hacia ella, por lo que la mujer o chica joven, en el momento del inicio de la relación, que es cuando se suelen producir estas formas de interaccionar, las admite y minimiza porque está muy enamorada, y se va desarrollando muy lentamente una situación de indefensión y vulnerabilidad.

Si protesta o no hace lo que se espera de ella, él incrementa su violencia, o retrocede y dejará pasar el tiempo poniéndole de manifiesto su falso amor.

Se pueden establecer una serie de etapas para explicar cómo se producen y se mantienen los malos tratos en una relación de pareja, al mismo tiempo, que nos ayuda a entender muchos de los problemas y sentimientos de las mujeres que sufren este tipo de violencia (Walter, 1979; Paz, 2009, 2011).

\subsection{Fase de acumulación de tensión}

Por cualquier cuestión nimia, el maltratador inicia su estrategia mostrándose irascible, cualquier comportamiento de la mujer le molesta y le causa enfado. La víctima, que no entiende lo que está pasando habla con esta persona para solucionar el inconveniente, de dónde procede el problema, cuál es el motivo de esta actitud, pero lo que consigue es que el hombre se enfade de manera más mordaz, propinando insultos y menosprecios a cambio. 
Ante esta incómoda situación la mujer queda paralizada, sin saber qué hacer, siendo acusada, entonces, por su maltratador, de que no vale para nada, que no sabe hacer nada. Si dice o hace algo, será siempre cuestionada y motivo de díscolo. Poco a poco, esta mujer víctima va cayendo en la red que, perversamente, le ha tendido su acosador, y que le costará trabajo salir.

El sentimiento de culpabilidad va mermando la capacidad de percepción de la realidad de las mujeres que se encuentran en esta situación, dudarán de la realidad que se les impone. Si le manifiesta la situación que está viviendo, él lo negará, afirmando que tiene la razón y que ella es la responsable de la situación que vive la pareja. Esto va a reforzar todavía más el comportamiento del hombre.

El maltratador, tomará la táctica de guardar una cierta distancia emocional con su pareja, ella creerá que la relación finalizará, cuestión que no quiere porque ha interiorizado desde temprana edad que tiene que velar por el bienestar de su familia, además de amar a este hombre que le inflige malos tratos habitualmente.

A pesar de que lo disculpa en innumerables ocasiones, observará que no obtiene el resultado que deseaba, y el varón continuará inexorablemente con su estrategia de maltrato, pues, lo que quiere lograr en definitiva es el control y dominación de su pareja a toda costa.

\subsection{Fase de explosión violenta}

En esta fase es cuando se producen los malos tratos físicos: golpes, patadas puñetazos; insultos e incluso agresión sexual. Se darán también, amenazas tanto para su vida e integridad física como la de sus hijos e hijas. En este período la mujer puede morir a manos de este hombre. Aunque ha querido adoptar los medios necesarios para salvar la relación, observa que no obtiene los resultados deseados, se encuentra impotente, frágil, y sin saber qué hacer.

Ahora el poder lo tiene este hombre que le inflige violencia, ella no tiene fuerzas para defenderse y reaccionar. Ha entrado en la llamada "indefensión aprendida", debido a los años que ha estado sufriendo maltrato psicológico y de otros tipos.

Es en esta etapa cuando suelen pedir ayuda, porque han visto peligrar su vida o la de sus hijos/as, pero él la buscará, le pedirá perdón, con lo que volverá al inicio. No hay que olvidar que esta mujer maltratada, ama a este hombre aunque le inflija malos tratos de todo tipo.

\subsection{Fase de "luna de miel" o conciliación}

El maltratador intenta de nuevo reconciliarse con su víctima adoptando el rol de hombre bueno y generoso, arrepentido del mal causado, y manifestando que nunca más volverá a realizar una cosa parecida. Cambia de tal manera, que la mujer cree que es cierto, que ha dado un giro a su cruel conducta y que todo va a ir bien. No se da cuenta de que es una nueva estratagema del agresor con el que convive.

\subsection{Escalada de la violencia}

Conseguida la confianza de su víctima, comenzará de nuevo este ciclo de la violencia, con una tremenda característica que lo diferencia de la primera vez que se inició, en este caso la violencia será cada vez más terrorífica; las etapas se acortarán, llegando incluso a desaparecer la de "conciliación”, como así lo han expresado muchas mujeres víctimas.

En otros casos la violencia no es cíclica, aparece de repente y no necesita justificación ni ritmo, en esta ocasión es más apropiado hablar de espiral de la violencia.

La mujer va perdiendo su poder, se da cuenta de que no puede controlar la forma de actuar de su pareja, no se trata de lo que ella realice o deje de realizar, los malos tratos que le 
ocasiona no tienen motivación. El agresor siempre negará y minimizará la situación, cuando se le pregunta por ello, haciendo dudar a la mujer, la cual se sentirá culpable.

El maltratador para conseguir el control de la mujer, así como causarle miedo dependencia, recurre a las siguientes tácticas:

a. Aislamiento de toda relación social, familiar, amistades, redes de apoyo, etc. para evitar que la mujer pueda tener otros criterios, comparar comportamientos, pedir y recibir ayuda (Nogueiras, 2006).

b. La desvalorización personal, las humillaciones, producen en la mujer baja autoestima, inseguridad, sentimientos de incapacidad, impotencia.

c. Demandas triviales para polarizar su atención, impidiendo que pueda dedicar su energía a sus propios proyectos o a buscar salidas, este tipo de macabras estrategias son denominados "micromachismos", (Bonino, 1999; Ferrer, 2007).

d. Mediante los golpes, amenazas, gritos, romper cosas, intimida a la víctima, crea un estado de pánico y terror.

e. Culpar a la mujer, minimizar la violencia, hacerse la víctima, provocar pena, chantajes emocionales que hacen dudar a la mujer de su responsabilidad y paralizan sus intentos de terminar con la relación.

f. Pequeñas concesiones, que crean una gran dependencia emocional, al no tener la mujer otras fuentes de afecto y relación.

\section{MITOS Y ESTEREOTIPOS DE GÉNERO}

Los mitos y estereotipos de género, permiten que la violencia contra las mujeres se perpetúe y se transmita de generación en generación. Siguiendo a Carmen Monreal, los estereotipos son creencias generalizadas sobre los atributos que caracterizan a determinado grupo social, y son transmitidos en el proceso de socialización (Monreal, 2008).

Los mitos y estereotipos poseen una serie de características que hace que se inserten en la sociedad de forma subrepticia, proponen modelos y marcan pautas de actuación; en definitiva ahorran el esfuerzo de analizar, reflexionar y evaluar críticamente los hechos, por lo que permiten resolver una situación de forma rápida, pero no acorde a la verdad.

Las personas que los comparten se ponen de acuerdo de forma fácil, lo que resulta cómodo y tranquilizador. Quien no esté de acuerdo queda excluido/a.

Son difíciles de desmentir por estar generalizados y formar parte de las convicciones sociales.

Aferrarse a ellos supone menos riesgos, que mantener una actitud más personal e individualizada. Son resistentes al cambio y al razonamiento. Contienen gran carga emotiva como el miedo, la culpa, el odio. Tienden a culpar a la mujer y a justificar al maltratador.

Influyen en los/as profesionales, amistades, familiares, vecindario, en los hombres violentos y en las propias mujeres en situación de maltrato, que se juzgan a sí mismas de acuerdo a esos mitos y creencias.

Como consecuencia de ellos, las mujeres víctimas se sienten culpables, dudan de sí mismas, con lo que se dificulta que se percaten de lo que les está sucediendo, con el objeto de pedir ayuda.

Es imprescindible cuestionar los mitos por ser asientos de la violencia en las relaciones de pareja, influyen en las personas, por lo que es necesario hacerlos conscientes.

Los mitos y estereotipos más frecuentes con respecto a la violencia dirigida a las mujeres, son (Mendi, 2005): 
5.1. Mitos y estereotipos sobre la violencia dirigida a las mujeres

1. Es una cuestión privada, se deben a crisis económicas.

2. Es gente sin principios ni moral, es natural e instintiva.

3. No puede ser evitada, disminuye en el embarazo.

4. Se exagera la realidad, son pérdidas puntuales de control.

5.2. Mitos y estereotipos con respecto a los hombres maltratadores:

1. Son hombres violentos, son alcohólicos, son violentos porque están en paro.

2. Son psicópatas, son impulsivos, son descontrolados.

3. Son sádicos, están locos o enfermos.

5.3. Mitos y estereotipos sobre los niños y niñas adolescentes, víctimas de la violencia

1. Fantasean, fabulan, mienten.

2. No se dan cuenta, no entienden, no sufren.

3. Su conducta es seductora, tienen precocidad sexual.

5.4. Mitos y estereotipos sobre las mujeres en situación de maltrato:

1. Provocan la violencia, son masoquistas, son pasivas.

2. Les pasa por aguantar la primera vez, son débiles y tontas.

3. Dicen "no" cuando quieren decir "si", son malas y se lo merecen.

4. Si tienen hijos e hijas, es mejor que aguanten.

Desmontando algunos estereotipos sobre la violencia de género. A continuación se van a exponer algunos estereotipos, socialmente establecidos y fácilmente creíbles, para seguidamente desmontarlos con datos empíricos:

\subsection{Desmontando estereotipos sobre violencia de género y condición social:}

Que las familias de los estratos inferiores de la sociedad recurran con más frecuencia, para la resolución de sus problemas, a las Fuerzas de Seguridad, no quiere decir que este tipo de conductas se ejerzan solamente entre estas familias. La violencia de género no entiende de clases sociales ni culturales, puede afectar a cualquier mujer, por el simple hecho de ser mujer (Ramonet, 2004).

\subsection{Desmontando estereotipos sobre violencia de género y enfermedad mental:}

El porcentaje de hombres que ejercen violencia contra sus parejas o exparejas, que se encuentran diagnosticados de enfermedad metal, oscila entre el $5 \%$ y el $7 \%$.

\subsection{Desmontando estereotipos sobre violencia de género y alcohol:}

El alcohol puede ser un desencadenante de una conducta violenta, pero no la causa, simplemente para reflexionar: ¿por qué el maltratador alcohólico, o bajo los efectos del alcohol maltrata solamente a su pareja y no a otras personas?

5.8. Desmontando estereotipos sobre violencia de género y culpa de las mujeres:

Este estereotipo descarga la responsabilidad de la violencia sobre las mujeres, por no comportarse con los roles que tradicionalmente se les ha asignado, cuando el único responsable de estos hechos es el maltratador. 


\section{CONCLUSIONES}

A modo de conclusión, hay unas cuestiones fundamentales que me gustaría destacar, primero, la violencia contra las mujeres son agresiones físicas psíquicas, sexuales o de otro tipo, estudiadas en este artículo, sin tener en cuenta el sujeto activo del hecho ni lugar de comisión, de esta forma lo enuncia Naciones Unidas.

La violencia de género en nuestro ordenamiento jurídico, castiga los hechos enunciados cometidos por el hombre en las relaciones de pareja o expareja, aún sin convivencia, con lo cual cualquiera de los ilícitos penales enunciados anteriormente, el hombre pareja o expareja los puede cometer, y de hecho ocurre así, en cualquier lugar distinto del domicilio. Por lo tanto denominar violencia de género y violencia doméstica como sinónimos, es un reduccionismo de la realidad.

Sí es cierto que se puede cometer violencia contra la mujer por parte de su pareja en su domicilio, pero no siempre ocurre de esta manera.

Además el Código Penal (1995), castiga en apartados diferentes del art. 153, la violencia de género en las relaciones de pareja o expareja (art. 153.1) de la violencia familiar o doméstica (art. 153.2), siempre que no exista habitualidad.

Aunque parezca una nimiedad, no es trivial lo expuesto, porque denominar a la violencia contra las mujeres, violencia doméstica es volver a los estereotipos y mitos que sustentan estas violencias, porque en definitiva lo que se pretende es que la mujer regrese al lugar donde un patriarcado mal entendido pretende, al ámbito privado, y con ello deshacer años de avances en igualdad de derechos entre los hombres y las mujeres.

\section{BIBLIOGRAFÍA}

ACALE, M. (2009). “Análisis del Código Penal en materia de violencia de género contra las mujeres desde una perspectiva transversal". REDUR 7, pp. 37-73.

AMORÓS, C. (2011). "Conceptualizar la violencia de género". Conferencia del $20^{\circ}$ aniversario del Curso de Historia de la Teoría Feminista. Madrid: Vídeo http://www.youtube.com/watch?v=Ztc6GS5 pXBM\&hd=1 (Consulta 25/8/2014).

BERBEL, E. (2004). Trátame bien. El maltrato físico y psicológico a examen. Barcelona: Alba.

BONINO, L. (1999). "Las microviolencias y sus efectos", en Revista Argentina de Clínica Psicológica, VIII: 221-233.

CALA, M. J. (2012). “¿Por qué algunas mujeres abandonan el procedimiento judicial por violencia de género? En M. J. Cala (dir.) La renuncia a continuar en el procedimiento judicial en mujeres víctimas de violencia de género. Sevilla: Consejería de la Presidencia e Igualdad de la Junta de Andalucía, pp. 79-114.

CANTERA, L. (1999). Te pego porque te quiero: La violencia en la pareja. Barcelona: Universidad Autónoma de Barcelona.

DE MIGUEL, A. (2005). "Los feminismos en la historia. El restablecimiento de la genealogía". En I. Torres (coord.) Miradas desde la perspectiva de género. Estudios de las mujeres. Madrid: Narcea, pp. 15-32.

FERRER, V. A. (2007). "La violencia contra las mujeres en la pareja o la visibilización de lo invisible". En ¿Todas las mujeres podemos?: Género, desarrollo y multiculturalidad. Actas del III Congreso Estatal Fll0 sobre igualdad entre mujeres y hombres Castellón: Fundación Isonomía, pp.166-175.

GAltung, J. (2003). "Violencia, Paz e Investigación sobre la Paz". Sobre la Paz. México DF.: Fontamara.

INSTITUTO ANDALUZ DE LA MUJER (2009). Abre los ojos el amor no es ciego. Día Internacional contra la violencia de género. Sevilla: Consejería para la Igualdad y Bienestar Social. 
LARRAURI, E. (2008). "Cinco tópicos sobre las mujeres víctimas de violencia u algunas respuestas del feminismo oficial". En P. Laurenzo Copello; $\mathrm{M}^{\mathrm{a}}$ L. Maqueda Abreu y A. Rubio Castro. Género, violencia y derecho. Valencia: Tirant lo Blanch, pp. 311-328.

LEAL, A. (2008). "Nuevos tiempos, viejas preguntas sobre el amor. Un estudio con adolescentes", en Revista Virtual y Sociedad. San José (Costa Rica): UNED.

LEY ORGÁNICA 10/1995, Código Penal, de 23 de noviembre (CP, 1995) BOE núm. 281, de 24 de noviembre de 1995, pp. 33987 y ss.

LEY ORGÁNICA 1/2004, de 28 de diciembre, de Medidas de Protección Integral contra la Violencia de Género (LO. 1/2004). BOE núm. 313, de 29 de diciembre de 2004.

LORENTE, M. (2004). "La violencia contra las mujeres un problema social", en Actas de las IV Jornadas: La violencia doméstica y sus efectos en el ámbito laboral. Granada: Instituto Andaluz de la Mujer.

LORENTE, M. (2010). "Medicina legal y forense y violencia de género", en Revista Española de Medicina Legal, 36 (3): 91-92.

LORENTE, M. y LORENTE. J. A. (1998). "Entre la realidad y el mito cultura". En Agresión a la mujer, maltrato, violación y acoso. Granada: Comares, p.85.

MAQUEDA, M. L. (2006). "La violencia de género. Entre el concepto jurídico y la realidad social". Revista Electrónica de Ciencia Penal y Criminología, 8: 1-13.

MELERO, N. (2010). "Reivindicar la igualdad de mujeres y hombres en la sociedad: una aproximación al concepto de género", en Barataria. Revista Castellano-Manchega de Ciencias Sociales, 11: 73-83.

MENDI, L. (2005). "Mitos y estereotipos sociales en relación al maltrato". En C. Ruiz-Jarabo y P. Blanco (dirs.) La violencia contra las mujeres: Prevención y detección. Madrid: Díaz de Santos, pp. 5770.

MINISTERIO DE SANIDAD, Servicios Sociales e Igualdad (MSSSI, 2013). Violencia de Género y Trata de Mujeres, accesible en http://www.msc.es/ssi/violencia Genero/home.htm, (consulta: 24/9/2014).

MONREAL, M. C. (2008). "Esquemas de género y violencia hacia la mujer". En López de la Cruz, L. (coord.) Ni el aire que respiras, pensamiento científico ante la violencia de género. Sevilla: Cajasol, pp. $89-108$.

NACIONES UNIDAS (1993). Declaración sobre la Eliminación de la Violencia contra la Mujer. Resolución de la Asamblea General 48/104, de 20 de diciembre de 1993. http://servindi.org/pdf/ DecEliminacionViolenciaMujer.pdf (consulta, 10/1/2013).

NACIONES UNIDAS. ASAMBLEA GENERAL (2006). Informe del Secretario General. Estudio a fondo sobre todas las formas de violencia contra la mujer. http://www.eclac.cl/mujer/noticias/paginas/1 /27401/InformeSecreGeneral.pdf, (consulta: 6/6/2014).

NOGUEIRAS, B. (2006). "La violencia en la pareja". En C. Ruiz-Jarabo y P. Blanco (dirs.) La violencia contra las mujeres: Prevención y detección. Madrid: Díaz de Santos, pp. 39-55.

PAZ. J. I. (2009). "Valoración de la peligrosidad de la violencia basada en el género". En http://www.interiuris.es/archivos/9_VALORACION_DE_LA_PELIGROSID.pdf. (consulta 3/9/2014). PAZ. J. I. (2011). "Entender a la mujer que sufre violencia de género". En C. Nieto-Morales (coord.) La violencia de género en el contexto de la globalización. España, pp. 440-453.

PERCY. C. (2009). "Teoría de conflictos de Johan Galtung", en Revista Paz y Conflictos, número 2: 60-81.

PERIS. M. (2009). Formación contra la violencia de género. Madrid: FOREM.

RAMONET, I. (2004). "Violencias masculinas". Le Monde Diplomatique (105).

RODRÍGUEZ, A. (2008). "Violencia en el ámbito familiar". En J. Collado (coord.) Fundamentos de Investigación Criminal. Madrid: Instituto Universitario Gutiérrez Mellado, pp. 139-210.

VALCÁRCEL, A. (2011). "La igualdad como preventiva de la violencia contra las mujeres: pautas para mirar el futuro en un mundo globalizado". En Curso de Verano de la Universidad Pública de Navarra:

Raíces de la violencia de género y claves para su erradicación. accesible en https://upnatv.unavarra.es /unes/valcarcel (consulta 1/9/2014).

VALPUESTA, M. R. (2008). "La violencia contra las mujeres un problema de igualdad.” En L. López de la Cruz (coord.) Ni el aire que respiras. Sevilla: Cajasol, pp. 33-68. 
VARELA, N. (2008). Feminismo para principiantes. Barcelona: Ediciones B.

WALKER, L. (1979). The battered woman. New York: Harper \& Row.

\section{Breve currículo:}

\section{Antonio Jesús Yugueros García}

Doctor por la Universidad Pablo de Olavide, en Desarrollo y Ciudadanía: Derechos Humanos, Igualdad, Educación e Intervención Social. Máster Oficial Interuniversitario en estudios de Mujeres, Género y Ciudadanía. Universidad Barcelona. Máster en Violencia de Género. Universidad de Valencia. Investigador de la Universidad Pablo de Olavide. Grupo Investigación: Valores, Familia, Igualdad y Relaciones Intergeneracionales (SE J468). 